\title{
Bile acid absorption kinetics in Crohn's disease on elemental diet after oral administration of a stable- isotope tracer with chenodeoxycholic-11, $12-\mathrm{d}_{2}$ acid
}

\author{
T NISHIDA, ${ }^{*}$ H MIWA, M YAMAMOTO, T KOGA, and T YAO
}

From the Second Department of Internal Medicine, Faculty of Medicine, Kyushu University, Fukuoka City, Japan, the Faculty of Pharmaceutical Sciences, Fukuoka University, Fukuoka City, Japan, and the First Department of Internal Medicine, School of Medicine, Fukuoka University, Fukuoka City, Japan

SUMMARY A non-radioactive tracer, deuterium, incorporated in chenodeoxycholic acid, was used to study bile acid absorption kinetics employing gas chromatography-mass fragmentography for its analysis. Eight patients with Crohn's disease and four control volunteers were administered chenodeoxycholic-11, 12- $\mathrm{d}_{2}$ acid. In order to obtain constant dietary conditions, they were fed by an elemental diet during the study. There were significant reductions of the biological half-life of chenodeoxycholic-11, 12- $\mathrm{d}_{2}$ acid, the pool size of chenodeoxycholic acid, and the total bile acid pool size in patients with Crohn's disease as compared with those in normal subjects. There was a marked increase in the relative concentration of ursodeoxycholic acid with a concomitant decrease of deoxycholic acid in patients with Crohn's disease, although such differences did not reach statistical significance. The present study confirms that there are some impairments of enterohepatic circulation of bile acids in patients with Crohn's disease.

Crohn's disease has frequently been discussed in relation to the associated problem of ileal lesions, ${ }^{1}$ which might be a cause of bile acid malabsorption. ${ }^{2}$ In 1977, Vantrappen et $\mathbf{a l}^{3}$ first determined the bile acid pool size in patients with Crohn's disease by using ${ }^{14} \mathrm{C}$-labelled compounds tracer techniques. ${ }^{4}$ Oral food intake, however, is diminished in these patients, because of gastrointestinal disorders, and that may influence bile acid kinetics.

The aims of the present investigation were: (1) to study the steady-state kinetics of enterohepatic circulation of bile acids in patients with Crohn's disease during constant dietary conditions, and (2) to develop stable-isotope tracer techniques using ${ }^{2} \mathrm{H}$-labelled bile acid and gas chromatography-mass fragmentography (GC-MF) without in vivo radiation exposure.

\section{Methods}

SUBJECTS AND EXPERIMENTAL PROCEDURE Investigations were performed in eight patients with

- Address for correspondence: Dr T Nishida, Second Department of Internal Medicine, Faculty of Medicine, Kyushu University, Maidashi 3-1-1, Higashiku, Fukuoka City, 812 Japan.

Received for publication 5 January 1982
Crohn's disease and four healthy volunteers (eight males and four females), aged between 16 and 50 years as listed in the Table. Informed consent was obtained in all the subjects. The diagnosis of Crohn's disease was made by clinical and radiographic examinations using air-barium double contrast technique. The characteristic features were linear ulcers, cobblestone mucosal pattern, asymmetry, skip areas, stricture, fistula formation, etc. Of the eight patients with Crohn's disease, six had lesions of the small bowel only and the remaining two had additional involvement of the large bowel. Medications were discontinued during the study in all patients except two, who received sulphasalazine (The Green Cross Corp., Japan). Patients with previous surgical treatment, liver damage, or diabetes mellitus were excluded from the present study.

In all the subjects, $50 \mathrm{mg}$ chenodeoxycholic-11, 12- $\mathrm{d}_{2}$ acid ( ${ }^{2} \mathrm{H}$-CDCA) (Merck Sharp \& Dohme Canada Ltd., Montreal, Canada), which proved to be of $95 \%$ enrichment with deuterium, was orally administered in the form of a capsule. After intramuscular injection of $10 \mu \mathrm{g}$ caeruletide diethylamine (Kyowa Hakko Co. Ltd., Japan), $2 \mathrm{ml}$ of fasting bile was obtained through an indwelling 
Table Subjects studied

\begin{tabular}{|c|c|c|c|}
\hline Subject & Age (yr) & Sex & Extent of disease \\
\hline \multicolumn{4}{|c|}{ Patients with Crohn's disease } \\
\hline HK & 44 & $\mathbf{F}$ & Ileum \\
\hline YY & 16 & $\mathbf{F}$ & Ileum, caecum \\
\hline SY & 17 & $\mathbf{M}$ & Ileum, jejunum \\
\hline KM & 28 & $\mathbf{M}$ & Ileum, colon* \\
\hline RT & 19 & $\mathbf{M}$ & Ileum, jejunum \\
\hline $\mathrm{OH}$ & 26 & $\mathbf{M}$ & Ileum, jejunum \\
\hline TY & 20 & $\mathbf{M}$ & Ileum \\
\hline IF & 25 & $\mathbf{F}$ & Ileum \\
\hline Mean & 24.4 & & \\
\hline \multicolumn{4}{|c|}{ Normal subjects } \\
\hline TM & 50 & $\mathbf{M}$ & \\
\hline NT & 21 & $\mathbf{M}$ & \\
\hline NT & 19 & $\mathbf{M}$ & \\
\hline EM & 22 & $\mathbf{F}$ & \\
\hline Mean & $28 \cdot 0$ & & \\
\hline
\end{tabular}

* Caecum, ascending colon, transverse colon, descending colon, sigmoid colon.

nasoduodenal tube before and $24,48,72$, and 96 hours after the administration of chenodeoxycholic-11, 12- $\mathrm{d}_{2}$ acid. Bile was kept at $-20^{\circ} \mathrm{C}$ until analysed. Biliary bile acid composition and decay curves of the isotope abundance of chenodeoxycholic-11, 12- $\mathrm{d}_{2}$ acid were determined by gas chromatography-mass fragmentography. Biliary bile acid composition was determined in a sample obtained before the administration of chenodeoxycholic-11, 12- $\mathrm{d}_{2}$ acid. The biological half-life of chenodeoxycholic-11, 12- $\mathrm{d}_{2}$ acid and the pool size and synthesis rate of chenodeoxycholic acid (CDCA) were calculated according to the open one compartment model. The total bile acid pool size was estimated by the gas chromatography-mass fragmentography's ratio of biliary bile acids.

Throughout the investigation, all the subjects studied were placed on an elemental diet (Ajinomoto Co., Japan), which provided $17.6 \%$ of its total nutritive values as amino acids, $79.4 \%$ as carbohydrates, and $\mathbf{0 . 6 6 \%}$ as lipids. To overcome the unpleasant taste, the diet was dissolved in water and the resultant emulsion was administered through an indwelling nasoduodenal tube from $8 \mathrm{am}$ to $12 \mathrm{pm}$ (12 midnight) at a fixed infusion rate. The diet delivered was 1500 to $1800 \mathrm{kcal} /$ day from 10 days to 92 days, on an average 34.9 days. The time interval from the initiation of the elemental diet to sampling was from five days to 27 days, on an average 10.9 days.

PREPARATION OF SAMPLES FROM BILE FLUID One hundred $\mu$ l of aspirated bile fluid was taken in a screw-cap tube and $1000 \mu \mathrm{g}$ of 12 keto-chenodeoxycholic acid (12 KCDCA) (Calbiochem-Behring Co.,
USA) was added as an internal standard. Saponification was performed with $6 \mathrm{ml} 4 \mathrm{~N} \mathrm{NaOH}$ methanol $(1: 1, v / v)$ at $80^{\circ} \mathrm{C}$ for 16 hours. After acidification with $6 \mathrm{~N}$ hydrochloric acid, the free bile acids were extracted three times with $5 \mathrm{ml}$ of ethyl ether. The ethyl ether was evaporated to dryness in vacuo, and the residual bile acids were methylated with $3 \mathrm{ml}$ diazomethane in ethyl ether. After evaporating the solvent, acylation was carried out by the addition of $1 \mathrm{ml}$ propionic anhydride-pyridine $(7: 3, v / v)$ at $80^{\circ} \mathrm{C}$ for eight hours. The solvent was removed with nitrogen gas stream. The residues of methyl ester propionate derivatives of bile acids were dissolved in $0.25 \mathrm{ml}$ methanol-acetone $(9: 1$, $\mathrm{v} / \mathrm{v})$, and were then submitted to gas chromatography-mass fragmentography measurements.

\section{INSTRUMENT AND CONDITIONS}

A JEOL JMS-D 100 gas chromatograph-mass spectrometer (JEOL Ltd., Japan) was used for gas chromatography-mass fragmentography measurements. Glass coil column, $100 \mathrm{~cm} \times 2 \mathrm{~mm}$ internal diameter, was packed with 3\% OV-17 coated on 80-100 mesh Shimalite (Shimazu Seisakusho Co., Japan). The temperatures of the column, injection port, and enricher were $280^{\circ} \mathrm{C}, 310^{\circ} \mathrm{C}$, and $310^{\circ} \mathrm{C}$, respectively. Helium gas carrier pressure was $2 \cdot 0$ $\mathrm{kg} / \mathrm{cm}^{2}$. Ionising current was $300 \mu \mathrm{A}$ and ionising voltage was $75 \mathrm{eV}$. Under these conditions, methyl ester propionate derivatives of individual bile acids were separated completely from each other on a gas chromatogram of total ion current, as demonstrated in Fig. 1. The respective relative retention times compared with deoxycholic acid were as follows: lithocholic acid, 0.61; chenodeoxycholic acid and chenodeoxycholic-11, 12- $\mathrm{d}_{2}$ acid, 1.14; ursodeoxycholic acid, 1.39; cholic acid, 1.73; 12 keto-chenodeoxycholic acid, 1.93.

\section{QUANTITATIVE ANALYSIS BY GAS}

\section{CHROMATOGRAPHY-MASS FRAGMENTOGRAPHY}

The mass spectra for methyl ester propionate derivatives of chenodeoxycholic acid and chenodeoxycholic-11, 12- $\mathrm{d}_{2}$ acid are presented in Fig. 2. The characteristic fragments, $\mathrm{m} / \mathrm{z} 370\left(\mathrm{M}^{+}\right.$ $518-2 \times 74$ ) for chenodeoxycholic acid and $\mathrm{m} / \mathrm{z} 372$ $\left(\mathrm{M}^{+}\right.$520-2×74) for chenodeoxycholic-11, 12- $\mathrm{d}_{2}$ acid represented the base peaks for gas chromatography-mass fragmentography. Likewise, the characteristic fragment ions selected for gas chromatography-mass fragmentography analysis of individual bile acids were as follows: $\mathrm{m} / \mathrm{z} 368$ for cholic acid; m/z 370 for chenodeoxycholic acid, deoxycholic acid, and ursodeoxycholic acid; $\mathrm{m} / \mathrm{z} 372$ for chenodeoxycholic-11, 12- $\mathrm{d}_{2}$ acid and lithocholic acid; $\mathrm{m} / \mathrm{z} 384$ for 12 keto-chenodeoxycholic acid. 
Fig. 1 Gas chromatogram of total ion current record of a mixture of methyl ester propionate derivatives of authentic bile acids.



The gas chromatography-mass fragmentography separation of a synthetic mixture of bile acids after derivatisation is demonstrated in Fig. 3. In order to obtain the calibration curves, the peak area ratios of known concentrations of bile acids to $4 \mu \mathrm{g} / \mu \mathrm{l}$ of 12 keto-chenodeoxycholic acid were determined by triangular method and the observed ratios were

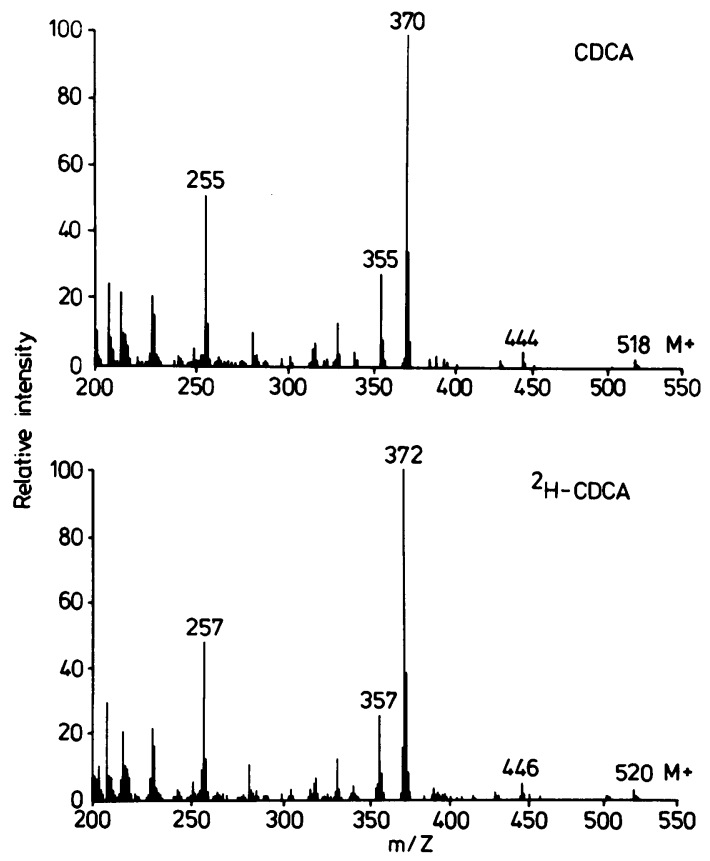

Fig. 2 Mass spectra of methyl ester propionate derivatives of authentic chenodeoxycholic acid (CDCA) and authentic chenodeoxycholic-11, 12- $d_{2}$ acid $\left({ }^{2} \mathrm{H}-\mathrm{CDCA}\right)$. plotted against the concentrations of bile acids to be analysed. The concentration ranges of calibration curves for individual bile acids were as follows: cholic acid, chenodeoxycholic acid and deoxycholic acid, from 0.25 to $5.0 \mu \mathrm{g} / \mu \mathrm{l}$; chenodeoxycholic-11, $12-\mathrm{d}_{2}$ acid, from 0.02 to $1.0 \mu \mathrm{g} / \mu \mathrm{l}$; ursodeoxycholic acid, from 0.1 to $1.0 \mu \mathrm{g} / \mu \mathrm{l}$; lithocholic acid, from 0.01 to $0.05 \mu \mathrm{g} / \mu \mathrm{l}$, respectively. Within these ranges, each calibration curve demonstrated good linear relationship through origin between peak area ratios and concentrations of the bile acids. As an illustrative example, a mass fragmentogram of methyl ester propionate derivatives of bile acids in the aspirate from a normal subject is shown in Fig. 4.

The data obtained by above method were expressed as mean \pm standard error. Student's $t$ test was used for comparison, and $p$ values of less than 0.05 were considered statistically significant.

\section{Results}

\section{BILE ACID KINETICS}

The mean value for the biological half-life of chenodeoxycholic-11, $12-\mathrm{d}_{2}$ acid was $1 \cdot 15 \pm 0.08$ day in eight cases with Crohn's disease, which was significantly $(\mathrm{p}<0.01)$ shorter than the $1.95 \pm 0.25$ day in four normal subjects (Fig. 5). The average values for the pool size of chenodeoxycholic acid were $434.0 \pm 60.6 \mathrm{mg}$ in Crohn's disease and $673.3 \pm 60.5 \mathrm{mg}$ in normal subjects (Fig. 6), and the mean values for the total bile acid pool size were $1323.0 \pm 173.6 \mathrm{mg}$ and $2290.9 \pm 327.3 \mathrm{mg}$, respectively (Fig. 7). These differences between the patients and normal subjects were of statistical significance $(p<0.02)$. The mean values for the synthesis rate of chenodeoxycholic acid were 
Fig. 3 Mass fragmentogram showing the separation of methyl ester propionate derivatives of authentic bile acids.

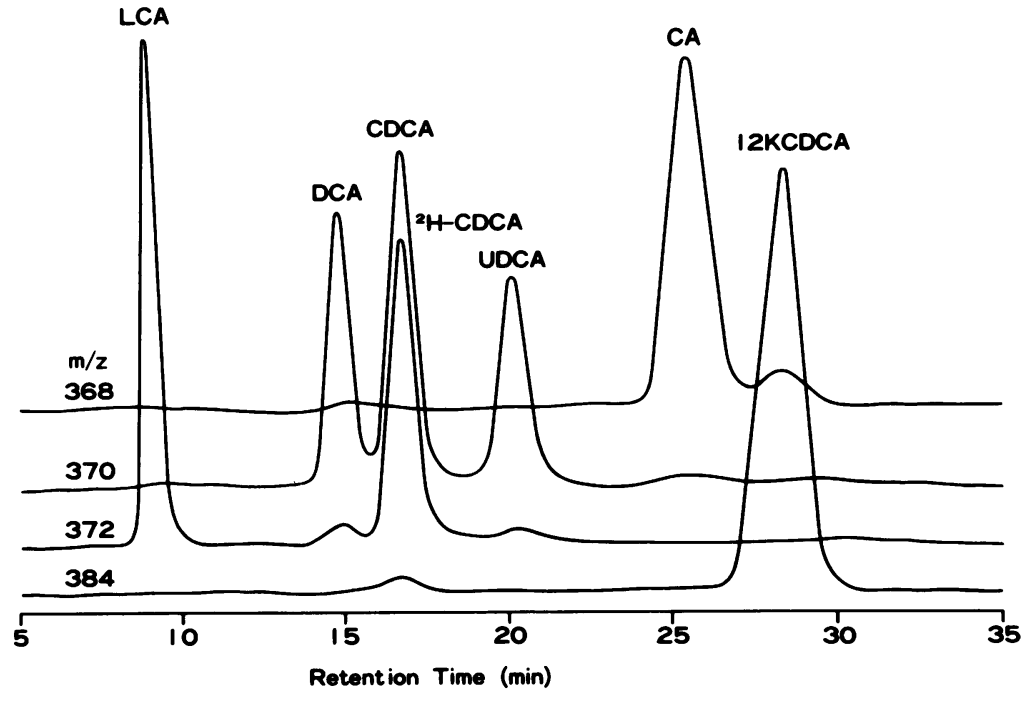

$266.3 \pm 40.6 \mathrm{mg} / \mathrm{day}$ in Crohn's disease and $256.9 \pm 49.0 \mathrm{mg} /$ day in normal subjects. There was no significant difference in the synthesis rate of chenodeoxycholic acid.

\section{BILIARY BILE ACID COMPOSITION}

The relative concentrations of deoxycholic acid in bile were $9.1 \pm 4.5 \%$ in patients with Crohn's disease and $21.4 \pm 7.4 \%$ in normal subjects, and the relative concentrations of ursodeoxycholic acid in bile were $8 \cdot 8 \pm 2.5 \%$ and $2.6 \pm 1.4 \%$, respectively. There was a tendency for the decrease in the relative concentration of deoxycholic acid and the increase of ursodeoxycholic acid in Crohn's disease. Such differences did not, however, reach statistical significance.

\section{Discussion}

Bile acid kinetics have been extensively studied in humans by using a radioisotope dilution technique. ${ }^{3-10}$ There are difficulties, however, in
Fig. 4 Mass fragmentogram of methyl ester propionate derivatives of bile acids in bile obtained from a normal subject.

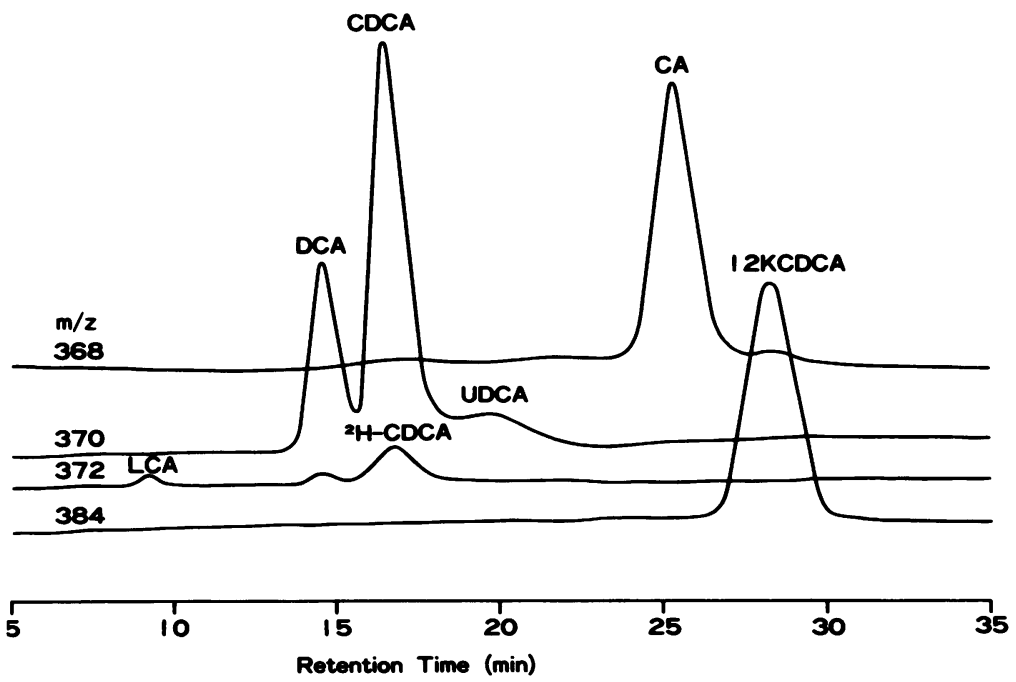




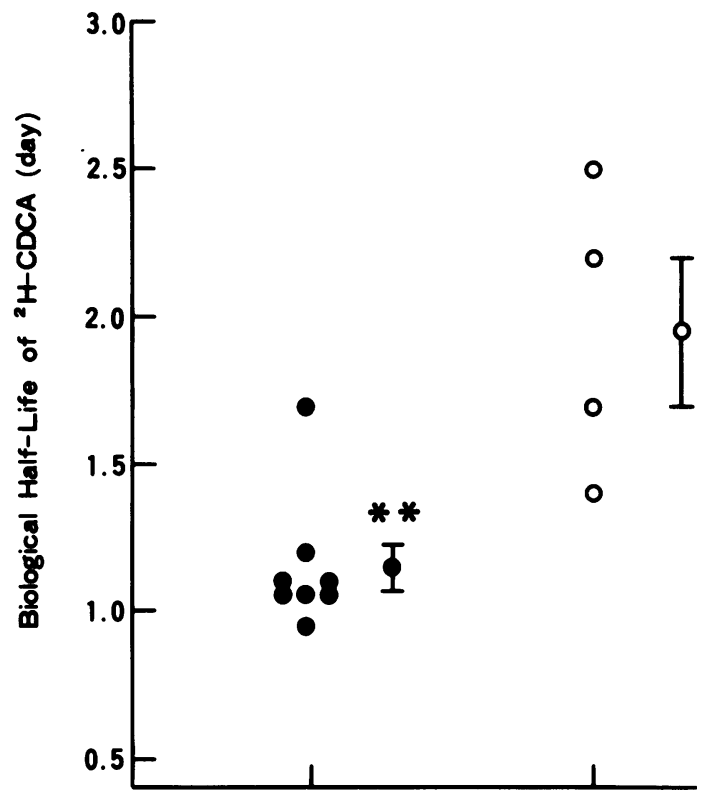

Fig. 5 Biological half-life of chenodeoxycholic-11, 12- $d_{2}$ acid. $\bullet$ Patients with Crohn's disease $(n=8)$, ○ normal subjects $(n=4),{ }^{* *}$ significant difference $(p<0.01)$ between patients with Crohn's disease and normal subjects. The line indicates the mean \pm standard error.

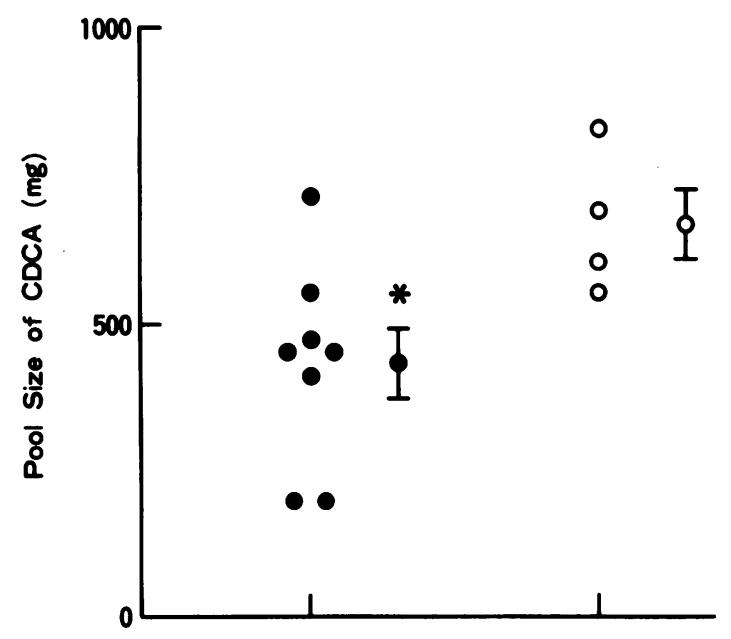

Fig. 6 Pool size of chenodeoxycholic acid. $\bullet$ Patients with Crohn's disease $(n=8)$, o normal subjects $(n=4)$, * significant difference $(p<0.02)$. The line indicates the mean \pm standard error.

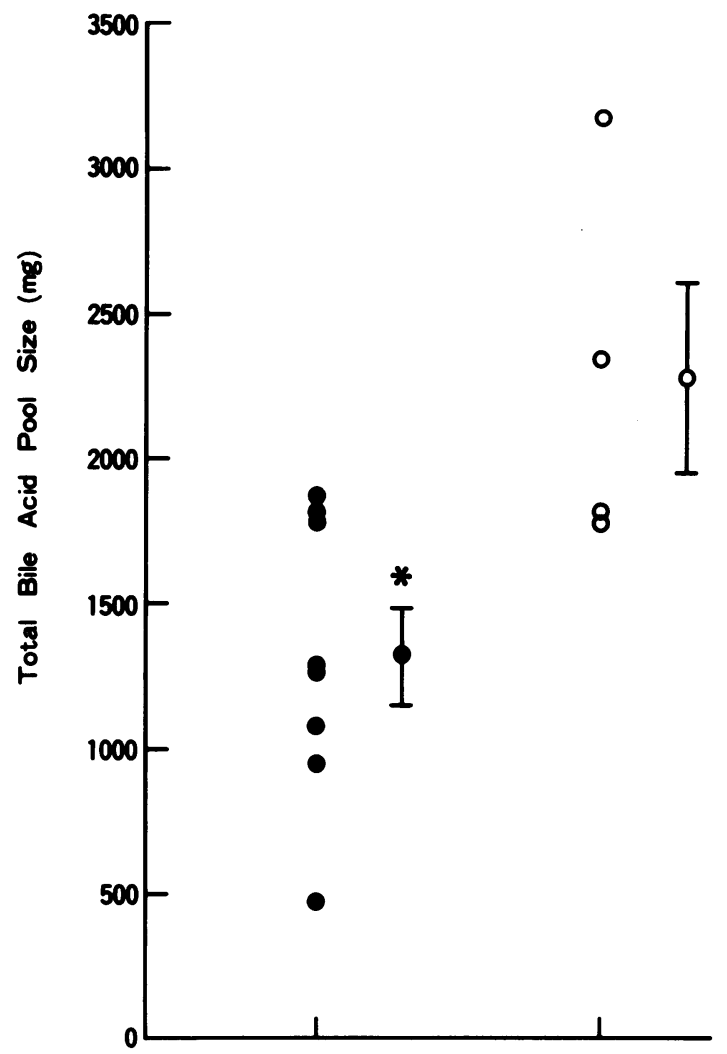

Fig. 7 Total bile acid pool size. $\bullet$ Patients with Crohn's disease $(n=8)$, O normal subjects $(n=4),{ }^{*}$ significant difference $(p<0.02)$. The line indicates the mean \pm standard error.

using radioactive tracers with such a long half-life as ${ }^{14} \mathrm{C}$ and ${ }^{3} \mathrm{H}$. Instead, the recently developed gas chromatography-mass fragmentography methods ${ }^{11-13}$ using stable-isotopes as a tracer ${ }^{16-18}$ are useful for these kinetics studies without radiation hazard. ${ }^{19}$ In the present study, a stable-isotope tracer with chenodeoxycholic-11, 12- $\mathrm{d}_{2}$ acid was used for measurement of bile acid kinetics. The stability of the $11,12-\mathrm{d}_{2}$ tracer atoms in the molecule was described by Balistreri et al. ${ }^{18}$

In Crohn's disease, the pool size of chenodeoxycholic acid, the total bile acid pool size, and the biological half-life of chenodeoxycholic-11, 12- $d_{2}$ acid were significantly reduced as compared with those in normal subjects; whereas the synthesis rate of chenodeoxycholic acid did not differ. Our results are compatible with those reported by Vantrappen et $a l{ }^{3}$ who found a reduction of the bile acid pool 
size in Crohn's disease by using radioactive tracers such as ${ }^{14} \mathrm{C}$-cholic acid and ${ }^{14} \mathrm{C}$-chenodeoxycholic acid.

It is known that conjugated bile acids are absorbed mainly at the ileum. ${ }^{20-22}$ Therefore, the diminished pool size of bile acid in Crohn's disease is considered to be due to impaired absorption at the ileum. ${ }^{23}$ This is the main site of lesion in this disease, as was demonstrated radiographically in our patients. Garbutt et al ${ }^{23}$ described possible associations between the bile acid malabsorption in Crohn's disease and several factors such as bile acid deconjugation due to small bowel bacterial overgrowth and short-circuiting of the enterohepatic circulation by more proximal absorption of the deconjugates.

Rutgeerts et al $^{9}$ have observed a similar reduction of the bile acid pool size in patients with isolated Crohn's colitis. From our results, little information has been obtained as to whether isolated involvement of the colon in Crohn's disease is related to the bile acid malabsorption, because there have been no such cases in our series.

Hepner, ${ }^{24}$ who found a significant increase in the pool size of primary bile acids on fat- and proteinrestricted diet, concluded that diet may affect the enterohepatic circulation of bile acids. To avoid such dietary effects on bile acid kinetics and to obtain a constant food intake, we gave an elemental diet with chemically defined composition and known alimentative calories through an indwelling nasoduodenal tube during the study; most patients with Crohn's disease have severe gastrointestinal signs and symptoms and are unable to take in a sufficient diet.

Many studies ${ }^{25-28}$ have shown that in most patients who had had ilectomy for various ileal diseases very little deoxycholic acid was detected in bile, probably because of a decrease in intestinal bacteria that may promote $7 \alpha$-dehydroxylation, ${ }^{25}$ or because of shortening of exposure time of cholic acid to the bacteria. ${ }^{28}$ Changes in the bacterial flora in Crohn's disease, however, are not always the same as those in ileal resection: in Crohn's disease, transmission of intestinal contents may be interrupted by strictures in the intestine, and disturbances of the intraluminal environment for the bacteria may occur because of inflammatory changes in the intestinal mucosa. The present study revealed a marked increase in the relative concentration of ursodeoxycholic acid with a concomitant decrease of deoxycholic acid in patients with Crohn's disease. Although such differences did not reach statistical significance, probably because of the small number of subjects, these results are in keeping with observations by Vantrappen et al. ${ }^{3}$

There have been some reports ${ }^{29-32}$ that an elemental diet is a promising method of inducing clinical remission in Crohn's disease. Long-term studies are needed, however, to discover whether an elemental diet improves the bile acid malabsorption in Crohn's disease.

It is concluded that the impaired bile acid absorption in Crohn's disease is confirmed by GC-MF method using stable-isotope without radiation hazard.

Thanks are due to Dr M Fujishima, Second Department of Internal Medicine, Faculty of Medicine, Kyushu University, for his valuable help in preparing the manuscript.

\section{References}

1 Mekhjian HS, Switz DM, Melynk CS, Rankin GB, Brooks RK. Clinical features and natural history of Crohn's disease. Gastroenterology 1979; 77: 898-906.

2 Lenz K, Jensen KB, Jarnum S. Bile acid metabolism and plasma protein turnover in Crohn's disease. Scand J Gastroenterol 1976; 11: 721-7.

3 Vantrappen G, Ghoos Y, Rutgeerts P, Janssens J. Bile acid studies in uncomplicated Crohn's disease. Gut 1977; 18: 730-5.

4 Lindstedt S. The turnover of cholic acid in man. Acta Physiol Scand 1957; 40: 1-9.

5 Danielsson $\mathrm{H}$, Eneroth $\mathrm{P}$, Hellström K, Lindstedt S, Sjövall J. On the turnover and excretory products of cholic and chenodeoxycholic acid in man.J Biol Chem 1963; 238: 2299-304.

6 Vlahcevic ZR, Bell CC, Buhac I, Farrar JT, Swell L. Diminished bile acid pool size in patients with gallstones. Gastroenterology 1970; 59: 165-73.

7 Pomare EW, Low-Beer TS. Measurement and validation of human bile salt pool size and synthesis. Clin Chim Acta 1974; 57: 239-48.

8 Duane WC, Adler RD, Bennion LJ, Ginsberg RL. Determination of bile acid pool size in man: a simplified method with advantages of increased precision, shortened analysis time, and decreased isotope exposure. J Lipid Res 1975; 16: 155-8.

9 Rutgeerts P, Ghoos Y, Vantrappen G. Bile acid studies in patients with Crohn's colitis. Gut 1979; 20: 1072-7.

10 Einarsson KA, Grundy SM, Hardison WGM. Enterohepatic circulation rates of cholic acid and chenodeoxycholic acid in man. Gut 1979; 20: 1078-82.

11 Eneroth P, Gordon B, Ryhage R, Sjövall J. Identification of mono- and dihydroxy bile acids in human feces by gas-liquid chromatography and mass spectrometry. $J$ Lipid Res 1966; 7: 511-23.

12 Sjövall J. Use of gas chromatography-mass spectrometry in the study of bile acid metabolism. In: Schiff L, Carey J Jr, Dietschy J. eds. Bile salt metabolism. Springfield, III: Thomas, 1969: 205-222. 
13 Miyazaki H, Ishibashi $\mathbf{M}$, Inoue $\mathbf{M}$, Itoh $\mathbf{M}$, Kubodera T. Simultaneous qualitative and quantitative analyses of bile acids by mass chromatography. J Chromatogr 1974; 99: 553-65.

14 Szczepanik PA, Hachey DL Klein PD. Characterization of bile acid methyl ester acetate derivatives using gas-liquid chromatography, electron impact, and chemical ionization mass spectrometry. J Lipid Res 1976; 17: 314-34.

15 Angelin B, Björkhem I, Einarsson K. Individual serum bile acid concentrations in normo- and hyperlipoproteinemia as determined by mass fragmentography: relation to bile acid pool size. J Lipid Res 1978; 19: 527-37.

16 Danzinger RG, Hofmann AF, Schoenfield LJ, Berngruber OW, Szczepanik PA, Klein PD. Measurement of bile acid kinetics in man using stable isotopes: application to cholelithiasis (abstract). Gastroenterology 1971; 60: 192.

17 Watkins JB, Ingall D, Szczepanik PA, Klein PD, Lester $R$. Bile-salt metabolism in the newborn: Measurement of pool size and synthesis by stable isotope technic. $N$ Engl J Med 1973; 288: 431-4.

18 Balistreri WF, Cowen AE, Hofmann AF, Szczepanik PA, Klein PD. Validation of use of $11,12-{ }^{2} \mathrm{H}$-labeled chenodeoxycholic acid in isotope dilution measurements of bile acid kinetics in man. Pediat Res 1975; 9: 757-60.

19 Hofmann AF, Hoffman NE. Measurement of bile acid kinetics by isotope dilution in man. Gastroenterology 1974; 67: 314-23.

20 Borgström B, Lundh G, Hofmann AF. The site of absorption of conjugated bile salts in man. Gastroenterology 1963; 45: 229-38.

21 Dietschy JM. Mechanisms for the intestinal absorption of bile acids. J Lipid Res 1968; 9: 297-309.

22 Tyor MP, Garbutt JT, Lack L. Metabolism and transport of bile salts in the intestine. Am J Med 1971; 51: 614-26.

23 Garbutt JT, Lack L, Tyor MP. The enterohepatic circulation of bile salts in gastrointestinal disorders. Am J Med 1971; 51: 627-36.

24 Hepner GW. Effect of decreased gallbladder stimulation on enterohepatic cycling and kinetics of bile acids. Gastroenterology 1975; 68: 1574-81.

25 Hofmann AF. Bile acid malabsorption caused by ileal resection. Arch Intern Med 1972; 130: 597-605.

26 Mcleod GM, Wiggins HS. Bile salts in small intestinal content after ileal resection and in other malabsorption syndromes. Lancet 1968; 1: 873-6.

27 Thaysen EH, Bruusgaad A, Eriksen B. Evaluation of the efficiency of bile salt recirculation in patients with terminal ileopathies by means of deoxycholate determination in duodenal aspirates. Scand J Gastroenterol 1970; 5: 39-48.

28 Kern F Jr. Disappearance of deoxycholic acid after ileal resection. Gastroenterology 1974; 64: 123-7.

29 Voitk AJ, Echave V, Feller JH, Brown RA, Gurd FN. Experience with elemental diet in the treatment of inflammatory bowel disease. Arch Surg 1973; 107: 329-33.

30 Goode A, Hawkins T, Feggetter JGW, Johnston IDA. Use of an elemental diet for long-term nutritional support in Crohn's disease. Lancet 1976; 1: 122-4.

31 Axelsson C, Jarnum S. Assessment of the therapeutic value of an elemental diet in chronic inflammatory bowel disease. Scand J Gastroenterol 1977; 12: 89-95.

32 O'Morain C, Segal AW, Levi AJ. Elemental diets in treatment of acute Crohn's disease. Br Med J 1980; 281: 1173-5. 